\title{
Tiotropium bromide in asthma patients: an alternative to inhaled long-acting beta-agonists?
}

\author{
M Lane \\ Respiratory Registrar, Queen Elizabeth Hospital, Gateshead, Tyne and Wear, UK
}

TITLE Tiotropium bromide step-up therapy for adults with uncontrolled asthma

Correspondence to $\mathbf{M}$ Lane, Respiratory Department, Queen Elizabeth Hospital, Sheriff Hill, Gateshead NE9 6BR, UK

JOURNAL N Engl J Med 2010; 363:I7I 5-26. doi:I0.1056/NEJMoa 1008770

DECLARATION OF INTERESTS No conflict of interests declared. tel. $+44(0) 7950963177$

e-mail matthew.lane@nuth.nhs.uk

\section{SUMMARY}

Asthma affects an estimated 5.4 million people in the UK.' Many patients remain symptomatic despite regular inhaled therapies. Given the burden of asthma and the heterogeneity of patients, the role of new therapeutic options requires evaluation. Tiotropium bromide has a well-established role in the management of chronic obstructive pulmonary disease (COPD). This is the first comprehensive study to evaluate its use in asthma.

The study recruited 210 adult patients with suboptimal asthma control despite British Thoracic Society (BTS) step 2 therapies (beclomethasone $80 \mu$ g, twice daily).

The triple-blind, placebo-controlled, three-way crossover design compared 14-week periods of step-up treatment of a long-acting anti-muscarinic (tiotropium $18 \mu \mathrm{g}$, once daily) versus a long-acting beta-agonist (salmeterol 50 $\mu \mathrm{g}$, twice daily) versus increased inhaled glucocorticoids (beclomethasone $160 \mu \mathrm{g}$, twice daily).

The primary outcome measure was the morning peak expiratory flow rate (PEFR). Secondary outcome measures included forced expiratory volume in one second $\left(\mathrm{FEV}_{\mathrm{l}}\right.$ ) (pre- and post-bronchodilator using the short-acting beta-agonist albuterol), asthma control days, rescue bronchodilator use, exacerbations and validated asthma questionnaires.

Tiotropium was shown to be superior to increased inhaled glucocorticoid with respect to the primary outcome measure (mean difference of $25.8 \mathrm{I} / \mathrm{min}$, $\mathrm{p}<0.00 \mathrm{I})$ and most secondary outcome measures, including the proportion of asthma-control days and the score on the Asthma Control Questionnaire.Tiotropium was also shown to be non-inferior to salmeterol for all assessed outcome measures and superior with regard to the bronchodilator response to albuterol ( $F E V$, mean difference of $0.07 \mathrm{I}, \mathrm{p}<0.00 \mathrm{I}$ ).

The authors conclude that tiotropium, when added to a regular inhaled glucocorticoid in patients with poorly controlled asthma, has an efficacy equivalent to salmeterol in improving lung function and symptoms.

\section{OPINION}

In adults with asthma who remain symptomatic despite low-dose inhaled glucocorticoid, options for step-up therapy include the addition of an inhaled long-acting beta-agonist (LABA) and increasing the dose of inhaled glucocorticoid. ${ }^{2}$ Additional options in selected patients include a trial of a leukotriene modifier and theophylline. ${ }^{2}$ Short-acting anti-muscarinics have been available for the treatment of bronchospasm for years. It is surprising that the role of long-acting anti-muscarinics (LAMA) in asthma has not been comprehensively evaluated before now.

While the study's primary outcome variable will be criticised, its secondary outcome variables are mostly patient-centred. A genuine clinically applicable evaluation of exacerbation rates was not possible given the short duration of the study.

The finding that tiotropium resulted in a greater improvement in PEFR and symptom control compared with doubling the dose of inhaled glucocorticoid is not surprising. Inhaled glucocorticoids have a relatively flat dose-response curve, such that doubling the dose is unlikely to result in significant clinical improvements. ${ }^{3}$

The most interesting finding of the study was that tiotropium was not inferior to salmeterol as step-up therapy. Recent concerns about infrequent but lifethreatening exacerbations associated with LABA use makes tiotropium an attractive alternative. ${ }^{4}$

A potential role for LAMA therapy in asthma lies in those patients who remain symptomatic despite a combination of inhaled glucocorticoid and LABA therapy (BTS stages 3-4). Peters and colleagues perhaps nod to this with the observation that the FEV did not increase following administration of a short-acting beta-agonist in patients taking a LABA but did in those taking LAMA. This role is currently being investigated (ClinicalTrials. 
gov number NCT00772538) in a study evaluating tiotropium in addition to usual care in patients with severe persistent asthma. Some clinicians are already using tiotropium in this context.

Although concerns have also been raised about a possible association between tiotropium and cardiovascular events in patients with COPD, this has not been borne out in larger studies. ${ }^{5-6}$ Further trials are required to determine the long-term efficacy and safety of tiotropium as an asthma therapy.

It will not be long before clinical trials of glucocorticoidLAMA combination inhalers are under way; perhaps in the near future 'triple-therapy' (glucocorticoid-LABALAMA) combination inhalers will be available for the treatment of asthma.

\section{REFERENCES}

I Simpson CR, Sheikh A. Trends in the epidemiology of asthma in England: a national study of 333,294 patients. J R Soc Med 2010; 103:98-106. doi: I0.1258/jrsm.2009.090348

2 Levy ML, Thomas M, Small I et al. Summary of the 2008 BTS/SIGN British Guideline on the Management of Asthma. Prim Care Respir J 2009; I8(SuppI I):SI-16. doi:I0.3132/pcrj.2008.00067

3 Bousquet J, Ben-Joseph R, Messonnier $M$ et al. A meta-analysis of the dose-response relationship of inhaled corticosteroids in adolescents and adults with mild to moderate persistent asthma. Clin Ther 2002; 24:I-20. doi:I0.10I6/S0I49-29I8(02)85002-0

4 Nelson HS,Weiss ST, Bleecker ER et al.The Salmeterol Multicenter Asthma Research Trial: a comparison of usual pharmacotherapy for asthma or usual pharmacotherapy plus salmeterol. Chest 2006 129:15-26. doi:10.1378/chest.129.1.15

5 Singh S, Loke YK, Furberg CD. Inhaled anticholinergics and risk of major adverse cardiovascular events in patients with chronic obstructive pulmonary disease: a systematic review and metaanalysis. JAMA 2008; 300:1439-50. doi: 10.100I/jama.300.12.1439. Erratum in: JAMA 2009; 301:I227-30.

6 Celli B, Decramer M, Kesten S et al. Mortality in the 4-year trial of tiotropium (UPLIFT) in patients with chronic obstructive pulmonary disease. Am J Respir Crit Care Med 2009; 100:434-50.

\section{CONFERENCING AND EVENTS}

The Royal College of Physicians of Edinburgh has a unique blend of rooms providing the perfect location for your conference, meeting or event. The Victorian Great Hall, galleried New Library and the Georgian Cullen Suite are wonderful settings for dinners and receptions. The modern Conference Centre seats up to 300 people in raked seating and is complemented by breakout rooms seating from 10 to 150 people, a keypad voting system and video conferencing. The College provides a stunning setting for weddings and receptions and is licensed for both civil and religious ceremonies. Discounts are available for Fellows and Members, medical conferences and charities.

For more information or for a quotation, please contact the Events Team on +44 (0) I 3 I 225 7324; email events@rcpe.ac.uk or visit http://www.rcpe.ac.uk/conferencing/index.php

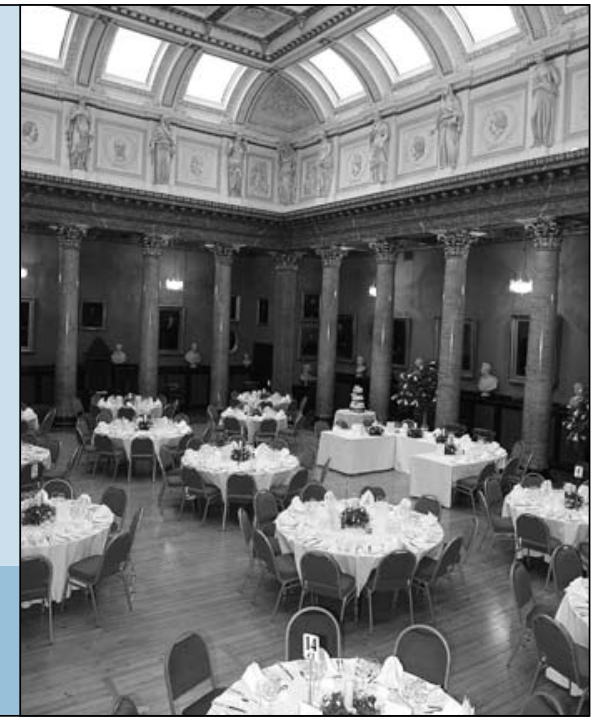

